\title{
The Effects of Climate Change on Soybean Production in Missouri and Its Implications on the Insurance Industry
}

\author{
Shravani Khisti, Amrita Vinjamury, Anastacia Son, Nafeesa Karim \\ Whitney High School, 16800 Shoemaker Ave., Cerritos, CA, 90703, USA; shravanik730@gmail.com
}

\begin{abstract}
As climate change intensifies, it increases anomalies in precipitation. This poses severe consequences to the agricultural industry, which will face a decrease in crop yields, and insurance companies, which will need to compensate large indemnities for farmers' losses. Soybeans, a major crop in the agricultural industry and the American economy, are extensively used in the diets of both humans and livestock. Thus, low soybean yields from precipitation anomalies may create dire risks for the economy. It is important to model the future of the agriculture and insurance industry so that farmers and insurance companies can prepare and take appropriate safety measures. To do this, we analyzed soybean yields and indemnities in Missouri, one of America's top soybean-producing states, by creating several regression models using previous data from the United States Department of Agriculture (USDA). Our models demonstrated both a decline in soybean yields and an increase in indemnities. After accounting for inflation, we projected the total indemnities paid in 2050 due to precipitation anomalies to be over double the number of indemnities paid in 2018. Although our model only focuses on soybeans, it is important to note that the effects of climate change will have damaging repercussions on other crops as well.
\end{abstract}

KEYWORDS: Agriculture; Analysis; Climate Change; Precipitation Anomaly; Indemnity; Regression; Soybeans; Missouri.

\section{- Introduction}

Soybeans are a major component of the human diet and are a nourishing livestock feed. The wide use of soybeans is largely due to the fact that they are $50 \%$ protein, making them highly nutritious. Soybeans also play a crucial role in the growing vegan lifestyle as plant-based alternatives in foods such as soymilk, plant-based meat products, and tofu. In 2019, plant-based food retails increased by over $11 \%$, making it a 4.5 -billion-dollar industry. ${ }^{1}$ Furthermore, soybeans are a versatile crop, and their components are often utilized in a variety of products such as margarine, paint, adhesive, fertilizer, and fire-extinguisher fluid. The most significant role of soybeans is in the diet of livestock. More than $70 \%$ of soybeans grown are used as feed for poultry and livestock such as cattle and pigs due to their high protein content and availability year-round. Thus, the soybean industry directly affects the meat industry. ${ }^{2}$ Consequently, the loss of soybeans would entail the loss of a major food source for livestock, causing humans to lose a significant component of their diet as well.

Soybeans were the top agricultural export of the United States in 2017, generating \$21.6 billion in revenue. The United States produced 108 million metric tons of soybeans in 2018, accounting for $34 \%$ of the world's soybeans, and has a $42 \%$ market share, making it the largest exporter of soybeans on a commodity basis. ${ }^{3}$

Over $80 \%$ of the United States' soybeans are grown in the Midwest, with Missouri being one of the leading ten states in soybean production. With approximately 95,000 soybean farms in Missouri, two-thirds of the state's total land acreage is allocated to soybean farms. ${ }^{4}$
As demand for soybeans continues to grow, Missouri will need to find a way to address the challenges it faces due to climate change as its economy will depend on it.

Considering that the United States is responsible for a large amount of soybean production in the world, it is imperative to analyze how climate change may impact soybean production. After examining the elements that affect soybean production, ${ }^{5}$ we found that precipitation irregularities have the greatest repercussions on indemnities. Missouri has been faced with greater precipitation anomalies in recent years, which pose a threat to soybean production. Studies show that there has been a significant increase in extreme precipitation occurrences from 1948 to 1978 , specifically in the Central United States as, “53\% of the total precipitation increase was a result of positive trends in the upper 10th percentile of the distribution". On the other end of the spectrum, "drought is expanding during the summer to cover 39\% of the contiguous United States (PDSI $\leq-3.0$ ), which is the largest extent since the 1950s." The repercussions of water deficit or water inundation affect the soybeans during their reproductive stage, leading to decrease in yield. ${ }^{7}$ For optimal growth, soybeans require adequate exposure to oxygen. After 24 hours in flooded soil, oxygen concentration can be close to zero. Flooded soils can contain 50 times more toxins than non-flooded soils, which can contaminate soybean plants and reduce yields as well. ${ }^{8}$

In 2018, $\$ 98.8$ million were paid as indemnities by insurance companies in Missouri for soybeans due to precipitation anomalies, including drought, excess precipitation, and flooding; this amount accounts for approximately $87 \%$ of total indemnities paid for soybeans due to all causes $(\$ 113,396,727)$, suggesting that much of the losses attributed to soybean production are due to precipitation anomalies. ${ }^{5}$ 
The relationship between climate change and agriculture has already been discussed by previous studies. For example, in a study published on the impacts of climate change in the Missouri, Iowa, Nebraska, and Kansas (MINK) region, the main focus was on carbon dioxide fertilizer on the agriculture and economy of the whole region. ${ }^{9}$ The study addressed multiple crops without specifically examining the effects on soybeans. Furthermore, there was no reference to possible solutions, and although the economic impact was analyzed, the potential repercussions on the insurance industry were not considered. A study conducted in India utilized different locations, weather patterns, soils, and temperatures to determine whether soybean yields were in fact affected by global warming. The authors found that there was a decrease of at least $10-20$ percent in soybean yield in all three future scenarios analyzed when the surface air temperature rose, and carbon dioxide concentrations increased. ${ }^{10}$ Delaying the sowing of soybeans in the growth season could help mitigate the consequences of these climate change impacts. In a similar simulation study conducted by the American Society of Agronomy, ${ }^{11}$ three soybean growth models were produced based on hypothetical weather scenarios. The findings concluded that the main threat to soybean production in the United States is the increased levels of atmospheric carbon dioxide in regions with limited water access.

Our paper addresses the economic impacts of climate change on soybeans while focusing specifically on the risks posed to insurance companies. Not only do we predict the impacts of climate change on crop yield, but we also provide potential solutions and recommendations to mitigate its consequences. Our research is specifically aimed to make future predictions and propose solutions to climate change impacts on soybean farmers in Missouri, insurance companies, and the agricultural industry as a whole. With the frequency of precipitation anomalies in Missouri showing upward trends due to climate change, it is necessary to identify ways to minimize losses attributed to decreases in soybean yields.

\section{Results and Discussion}

The slope we found from the NOAA of +0.94 inches per decade indicates that there will likely be a steady increase in precipitation in Missouri. Furthermore, Missouri can expect to see extreme anomalies as seen by how Figure 1's moving average (the red trend line) shows drastic irregularities in recent years. Such extreme anomalies, specifically floods, will have negative impacts on soybean farmers.

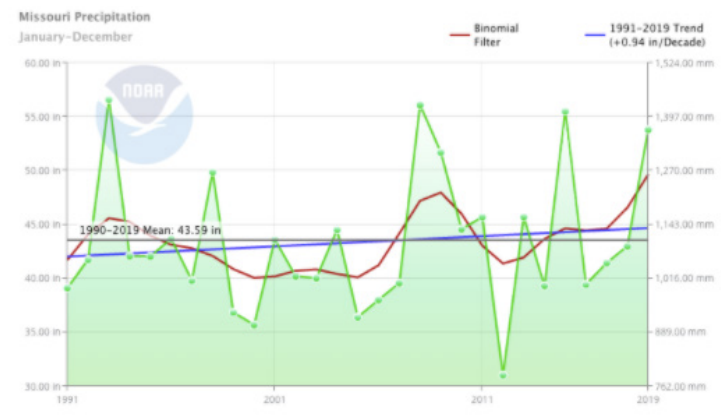

Figure 1: Precipitation anomaly (inches).
We found the average precipitation value in 2050 to be 56.029 inches. However, this value is also an underestimate because it was calculated using the underestimated precipitation anomaly value. This means that Missouri can expect to see approximately 56.029 inches of rain or more in 2050 .

After plotting the quadratic regression model for the relationship between soybean yield and precipitation anomaly, we saw a moderately strong relationship correlation coefficient of 0.617 . This value is significant because it indicates that precipitation anomalies have a negative impact on soybean yield. As anomalies become more extreme and unpredictable in the future, soybean farmers in Missouri will need to mitigate the risks posed by excess precipitation and floods.

The percent yield computed for 2050 is $96.88 \%$ and serves as an indication of the negative impacts of the high precipitation values and anomalies on the industry. Although this may seem like a high percent, it is lower compared to the percent yields of other years which ranged between 98\% 99\%. Looking at the percent yields for previous years, only the years 1993 and 2008 produced lower percent yields, which can be attributed to the Great Flood of '93 and the June Floods of '08.12 This shows that in the future, farmers will need to invest more money on solutions to increase their yield in order to ensure that their profits and farms are not severely impacted by extreme precipitation anomalies.

Using a least squares regression line (LSRL), we estimated the total indemnities paid for precipitation anomalies in 2050 to be approximately $\$ 141,786,302.90$. The estimated total indemnities paid using our exponential regression model will be $\$ 1,040,995,171$. The indemnity value in 2050 , according to our power model, will be $\$ 75,946,940.62$. It is unrealistic that the indemnities paid will continue to increase at an exponential rate in future years, so Missouri should expect to pay an amount that is between the estimates found in the power model and the LSRL.

When adjusted for inflation, the total indemnities paid in 2050 based on the 96.88 percent yield is between $\$ 492,694,498.80$ and $\$ 919,817,584.03$ where the lower bound is the adjusted value from the power model and the upper bound is the adjusted value from the LSRL. It was necessary to create a range, as on one hand, the power model is the most accurate and so a value closer to the lower bound is expected, however on the other hand, it is highly likely that total indemnities paid will be much greater due to the greater frequency of extreme precipitation anomalies.

\section{Recommendations for the Agricultural Industry:}

In the case of droughts, which may become more frequent in the future, policies that encourage drip irrigation systems can be implemented. Additionally, using technology such as pivot control panels to remotely control and track systems, variable-frequency drives to optimize the speed and pressure of water pumps, and soil moisture sensors to monitor soil can be beneficial. ${ }^{13}$ These technologies control and monitor irrigation systems, allowing for a more conserved and effective use of water. In order to combat the losses suffered due to lower percent yields, farmers can choose to plant soybeans before corn as these two crops are usually planted together. 
Planting soybeans before corn augments yield potential without increasing cost. ${ }^{14}$ This will also remedy the problem of delayed planting due to heavy precipitation during growing seasons. Farmers also must take measures after floods to retain nutrient levels of soil for soybean growth. After floods, fungi in the soil, such as Arbuscular mycorrhizae are lost. These fungi are crucial to maintain the nutrient levels of the soil, and farmers must reestablish fungi populations after flooding. ${ }^{15}$ One way to do so is to plant cover crops to provide protection from debris and stimulate microbial and fungal activity. In order to manage the quality of soil it is important to implement solutions that deal with run-off properly and maintain correct drainage systems, such as loosening compacted soil beds to reopen pores and adjusting cropping patterns by splitting long fields to decrease erosion from wind. ${ }^{16}$ Additionally, to increase pest resistance, genetically modified crops (GMOs) are often implemented. While studies show that GMOs enable lower use of insecticides, consumers are hesitant to purchase crops that have been genetically modified. Increased research and awareness on the actual effects of GMOs on human health should be implemented to dispel unwarranted stigmas. ${ }^{17}$

\section{Recommendations for Insurance Companies :}

As seen in Figures 1 and 2, the frequency of precipitation anomalies, specifically occurrences of floods and excess precipitation, will most likely continue to increase, so insurance companies should design appropriate policies as preventative measures. One policy that can be implemented is a RainyDay Fund, where insurance companies have a safety reserve for Emergency Farm Loans, specifically for high-risk areas, that must be paid when rainfall passes a certain threshold. This ensures that insurance companies will have enough money to compensate for the damage. Insurance companies can analyze historical data to find which agricultural areas in Missouri are at a higher risk of flooding and excess rainfall and to find the amount of rainfall that preceded severe storms or floods. They can then set a predetermined amount of money to be paid as a one-time fee when precipitation exceeds a measurable parameter. Recently, Missouri's governor called for a $\$ 100$ million Rainy Day Fund, which could help bring state savings up to $10 \%$ in general revenue, along with Missouri's existing Budget Reserve Fund. ${ }^{18}$ Other preventative measures that can be taken include providing discounted premiums to farmers who take preventative measures such as developing weed management plans that prevent crop damage from new weed growths, which occur when flood waters wash away the top layers of soil and reveal weeds buried deep in the tillage. Developing adequate drainage systems, such as water courses for flooded water to quickly drain into rivers and creeks, should also be encouraged. Farmers will be less likely to file claims for losses due to floods as they will be prepared to deal with weeds and to minimize flooded crops. In the past, the government has been accommodating when farmers lobbied for greater subsidies to be paid. In 2019, for example, soybean farmers threatened to stop all trade due to the consequences that they faced from the tariffs that the US President placed on Chinese goods. ${ }^{19}$ When soybean farmers lobbied Congress, the Federal Government announced a new deal that entailed 16 billion dollars of aid, which overcompensated farmers greatly, causing losses to the government. The Federal Government can prevent such losses in the future by developing a concrete method to accurately quantify how much farmers need to be compensated and creating criteria to ensure eligibility for the amount of aid farmers need after floods. On the other hand, insurance companies can benefit from the government's generous support of farmers by investing money to lobby Congress for increased subsidies on crop insurance policies, specifically yield protection policies, instead of Revenue Protection Insurance Plans. Furthermore, lobbying Congress allows for huge revenue returns which would be very beneficial to Congress. By investing in lobbying, many corporations received " $22,000 \%$ in returns meaning 220 dollars for every dollar invested." ${ }^{20}$ Although this value may be an overestimate, insurance companies can expect high returns for the amount invested.

\section{Public Policies :}

One public policy that can be utilized is conducting frequent soil tests to ensure that soil that has been affected by floods or excessive rainfall has adequate infiltration and nutrients. Flooded soil often has changes in composition due to exposure to various elements such as silicon, nitrogen, phosphorus, and potassium ${ }^{21}$ from flood water. When soil does not have proper infiltration, flood waters can carry away nutrients and prevent soil from holding clean water. Through soil tests, the federal government can ensure that farmers are aware of the nutrients that the soil is lacking and the water concentration, which has a large impact on the quality of the yields as well as the types of fertilization used in the next season. Frequent soil tests can help to prevent damage from pest invasions as well as inadequate soil conditions. For example, soils with low $\mathrm{pH}$ or low nutrient levels, which are often results of flooding, have a difficult time resisting pest invasions. In months after flooding, farmers should frequently test soil to ensure that soybeans have the means to effectively tolerate insect feeding. ${ }^{22}$ Since certain areas in Missouri are at a higher risk of drought or floods, examining the land will clarify which areas have the best soil composition, best infiltration, and lowest risk of severe precipitation anomalies. Lastly, government agencies such as the Cybersecurity and Infrastructure Security Agency can develop infrastructure, such as flood walls, in high-risk farming lands to protect farming lands from floods and droughts to minimize the costs of damage on soybeans.

\section{Other Recommendations:}

The agricultural industry can increase awareness of their needs through independent agricultural organizations. Institutions such as the American Soybean Association should cooperate with the government in order to develop practical solutions for environmental and food safety issues. Since farm and commodity organizations have the most experiential knowledge, their input should be highly valued by the government. By working cooperatively, new policies can be created to protect soybean farmers and consumers through greater education on product safety and handling. To minimi- 
ze carbon emissions, we recommend further research on biofuels with coconuts, starch, sugarcane, and corn bases as a renewable energy source. ${ }^{23}$ The implementation of biofuels could potentially reduce the amount of carbon emissions released into the atmosphere and reduce US dependence on foreign energy sources. Fossil fuels provide $80 \%$ of the US energy needs, ${ }^{24}$ and approximately $19 \%$ of US petroleum is imported from foreign energy sources. ${ }^{25}$ By shifting to produce biofuels, instead of nonrenewable petroleum, it could take as little as 15 years to offset the greenhouse gas emissions produced by liquid fossil fuels. ${ }^{26}$ In addition, switching to biofuels could reduce the amount of particulates in the air, as diesel has an opacity percent of $2.9 \%$, while biofuels such as B5 and B100 have opacity percentages of $2.4 \%$ and $1.1 \%$, respectively. ${ }^{27}$ However, there are several concerns with the use of certain biofuels, like corn ethanol, including ethical concerns, increased prices of food products, and erosion of land. ${ }^{28}$ These positive and negative implications surrounding biofuels need to be investigated further. For a long-term solution, the government, specifically the US Department of Agriculture, should collect accurate data and frequently update data on soybean yields. By updating data frequently, the USDA would more effectively monitor trends and make accurate predictions in the future. The NOAA should also frequently collect data on rainfall measurements and flooding incidents for this purpose as well.

If these recommendations are taken into consideration, farmers will be more prepared for damages from precipitation anomalies, insurance companies and the government will be less susceptible to monetary loss, and other institutions such as the food industry will benefit as well.

\section{Limitations:}

Our projections are based on historical climate patterns, so they may not be accurate predictions since future climate patterns will be affected by other factors, such as increased amounts of carbon emissions and new regulations. Since excess precipitation is a more prevalent issue in Missouri, we did not consider the negative anomaly value which accounts for droughts. Although our calculations considered all the acres to be grown under the same conditions, we also realize that distinct areas grow soybeans differently, at different times throughout the year, with different soil compositions. Many soybeans are genetically engineered to be resistant to precipitation anomalies, and irrigation systems are implemented to limit losses due to precipitation, but this was not taken into account when calculating percent yield. We created multiple models to consider over and underestimations and accounted for the rate of inflation. However, our calculations were based on extrapolations.

\section{- Conclusion}

Based on our model, it is likely that severe floods and droughts due to precipitation anomalies will become a more alarming issue in the future for soybean farmers in Missouri, insurance companies, and other institutions. As precipitation anomalies increase, all stakeholders must prepare to deal with extreme irregularities harming soybean yield. Considering the value that soybeans hold in the agricultural industry and in the US economy, it is crucial that all parties including insurance companies take preventative measures to reduce the risk of damage on soybeans. Soybeans are the foundation of a wide variety of sectors. As climate change heightens, it is imperative to address and prevent the destruction of this precious crop. The cultural, political, and environmental repercussions from soybean devastation can only be avoided through the cooperation and immediate response of all parties both domestically and globally.

\section{- Methods}

\section{Step 1:}

As shown in Figure 1, we see that as years go on, precipitation becomes more frequent and irregular, exemplified by the red moving average trend line. While examining soybean production in Missouri, we noticed that it is negatively impacted by precipitation, which we anticipate will increase in irregularity. This indicates that as climate change increases, the frequency of precipitation anomaly occurrences increases as well. To prove this, we first examined precipitation anomalies from 1991-2019 using data from the NOAA. With the given statewide time series tool, we found that the rate of change of precipitation per decade is a positive value $(0.94$ inches), indicating that precipitation is increasing in Missouri. Thus, we decided to examine if a linear regression was an appropriate model to extrapolate and estimate the precipitation anomaly value in 2050 .

Step 2:

Using the precipitation data from NOAA for 1991-2019, letting $\mathrm{x}$ be decade (1991 as $\mathrm{x}=0$ ) and $\mathrm{y}$ be average precipitation, we performed a linear regression to obtain an equation for predicted precipitation in inches per year:

$\mathrm{P}(\mathrm{x})=0.94 \mathrm{x}+42.274$

This model resulted in a correlation coefficient of $r=0.12518$, a coefficient of determination of $r^{2}=0.01567$, and a standard deviation of residuals of $s=0.8515$.

To predict the mean precipitation in 2050 , we will use an $\mathrm{x}$ value of 5.9 decades:

$\mathrm{P}(5.9)=0.94(5.9)+42.274=47.82$ inches

Since $s=0.8515$, we know that predictions made with our linear model will deviate from the true precipitation values by about 0.8515 inches per year. With this in mind, we are approximately $95 \%$ confident that the actual mean precipitation value for 2050 is likely between 46.117 and 49.523 inches per year, which is plus and minus $2(0.8515)$ from the predicted value.

\section{Step 3:}

After using the linear regression model to calculate mean precipitation in 2050 (47.82 inches), we decided to estimate the precipitation anomaly value in 2050 based on the precipitation anomaly values from 1991-2019. We estimate it to be 47.82 . We decided to use the absolute value of each precipitation anomaly value because we want to calculate the approximate deviation from the mean of 43.59 inches. We graphed a linear regression equation with years as the dependent variable and |precipitation anomaly| as the independent variable to predict the |precipitation anomaly| value in 2050 . 


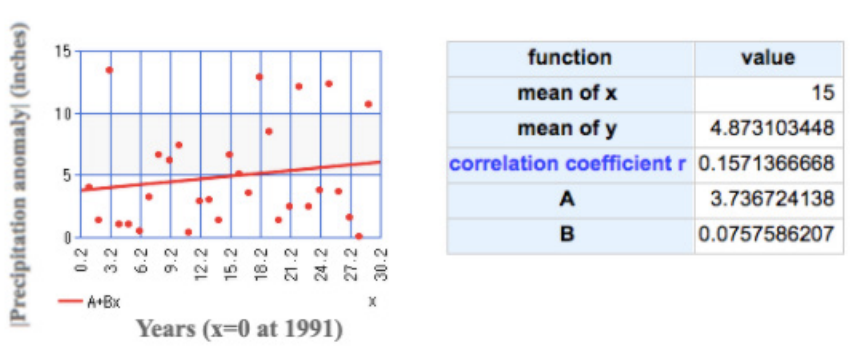

Figure 2: Absolute value of precipitation anomaly (inches) vs years.

$\mathrm{A}(\mathrm{x})=0.0758 \mathrm{x}+3.7367$, where $\mathrm{x}=0$ represents 1991

Looking at Figure 2, we saw a weak linear relationship between years and |precipitation anomaly|, with a correlation coefficient of 0.157 . A low correlation implies that there is no firm incremental increase or decrease in |precipitation anomalies | as years increase; this further validates our claim that climate change will make precipitation anomalies even more erratic in the future. Despite the low correlation value, we still used our model as a baseline as we are underestimating the value. With this model, we are able to obtain an estimated |precipitation anomaly| for 2050 of:

$\mathrm{A}(59)=0.0758(59)+3.7367=8.2089$

As seen in step 1, the precipitation in Missouri shows an increasing trend. As a result, we assumed that the precipitation anomaly in 2050 will be a positive value. Using this predicted precipitation anomaly along with our predicted mean precipitation from step 2, we are able to find the expected precipitation for 2050 as $47.82+8.2089=56.029$ inches.

\section{Step 4:}

In order to confirm that precipitation anomalies negatively affect the soybean industry, we examined the relationship between the two from 1991 to 2019. Considering the data, we presumed that years with large anomalies — or years where there is a larger deviation from the mean precipitation - would produce a smaller yield, while years with an optimal amount of precipitation would produce a larger yield. If this was the case, it would result in a negatively oriented parabolic curve. For this reason, we chose to create a quadratic regression model with precipitation anomaly as the independent variable and percent yield (acres harvested divided by acres planted) as our dependent variable.

After plotting, in Figure 3, we saw a moderately strong relationship with a correlation coefficient of 0.617 ; however, we noticed a potential outlier in 1993, where the percent yield was relatively low, and the precipitation anomaly was unusually high. Interestingly, that year was marked by the Great Flood of 1993 that devastated the Midwest, including Missouri. During this flood, precipitation exceeded the mean by 13.47 inches of rain, and cost almost 15 billion dollars in total losses for the country. ${ }^{11,29}$

$$
\mathrm{Y}(\mathrm{x})=0.991-0.000752 \mathrm{x}-0.000239 \mathrm{x} \wedge 2
$$

After plotting, in Figure 3, we saw a moderately strong relationship with a correlation coefficient of 0.617 ; however, we noticed a potential outlier in 1993, where the percent yield was relatively low, and the precipitation anomaly was unusually high. Interestingly, that year was marked by the Great Flood of 1993 that devastated the Midwest, including Missouri.
During this flood, precipitation exceeded the mean by 13.47 inches of rain, and cost almost 15 billion dollars in total losses for the country. ${ }^{11,29}$
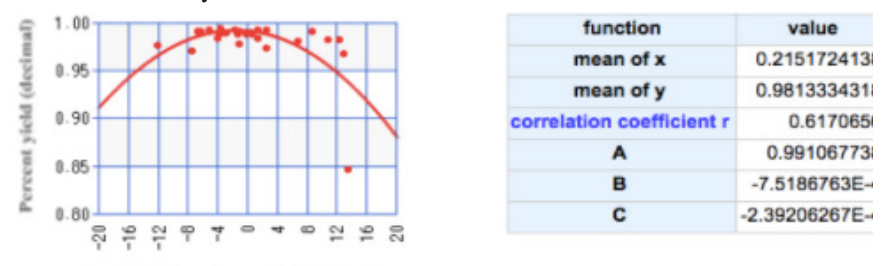

Precipitation Anomaly (inches)

Figure 3: Precipitation anomaly vs percent yield in Missouri, including Grear Flood of 1993.

Thus, we decided to re-examine the strength of the relationship between precipitation yield and precipitation anomaly by excluding the year 1993. In doing so, we observed a slightly lower correlation coefficient of 0.572 .

After creating the quadratic regression model, we realized that a linear model might be more appropriate. Hence, we created an LSRL for precipitation anomaly(inches) vs. percent yield. When including 1993 in the LSRL, we saw a correlation coefficient of -0.44 , and when we excluded 1993 the correlation coefficient was -0.25 .

Examining the strengths of these different models along with the fact that extreme floods would increase in the future as global warming persists ${ }^{30}$ (points such as 1993 would occur with increasing frequency), we concluded that the quadratic model with the extreme value is most appropriate. Thus, we will use the equation from our first model.

$\mathrm{Y}(\mathrm{x})=0.991-0.000752 \mathrm{x}-0.000239 \mathrm{x}^{\wedge} 2$

Step 5:

Using the precipitation anomaly found in step 3 and the model for percent yield from step 4, we predicted the soybean percent yield for 2050 to be approximately $96.88 \%$ soybeans harvested/total amount of soybeans planted.

$$
\begin{aligned}
& \mathrm{Y}(\mathrm{x})=0.991-0.000752 \mathrm{x}-0.000239 \times 2 \\
& \mathrm{Y}(8.2)=0.991-0.000752(8.2)-0.000239(8.2) 2=0.9688 \\
& \text { Step 6: }
\end{aligned}
$$

Overall, we were able to see that high precipitation anomalies generally reduce soybean yield; we predicted that lower yield would indicate an increase in indemnity cost as well. We utilized the data from the USDA RMA and adjusted each data point for inflation, so the monetary value would match the value of the dollar in 1991. We used the compound interest equation, $\mathrm{A}=\mathrm{P}(1+\mathrm{r}) \mathrm{t}$, along with the inflation rate of $3.22 \% .{ }^{31}$ Using the adjusted values, we created a scatterplot and least squares regression line of indemnities paid due to precipitation anomalies against years.

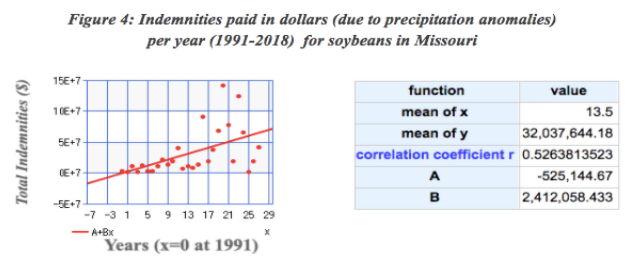

Figure 4: Indemnities paid in dollars (due to precipitation anomalies) per year from 1991-2018 for soybeans in. 

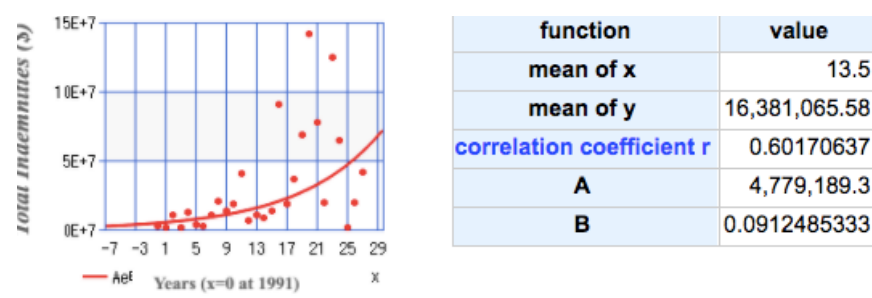

Figure 5: Indemnities paid in dollars (due to precipitation anomalies) per year from 1991-2018 for soybeans in.

Step 7:

Since the correlation coefficient in Figure 4 was only 0.526 , we examined the pattern further and decided to explore how an exponential regression curve would fit years vs. total indemnities paid due to precipitation anomalies.

$\mathrm{M}(\mathrm{x})=4779189.3^{*} \mathrm{e}^{\wedge} 0.0912485 \mathrm{x}$

This exponential model in Figure 5 seems to be a better fit to the data as compared to the linear model because the correlation coefficient is 0.602 . Using this exponential model, we can predict the indemnities paid due to precipitation:

$\mathrm{M}(59)=4779189.3^{*} \mathrm{e}^{\wedge}(0.0912485)(59)=1,040,995,171$

The value $\$ 1,040,995,171$ is most likely an overestimate since it is unlikely for the exponential pattern, we see from 1991-2018 to continue all the way until 2050.

\section{Step 8:}

Although the exponential model yielded a correlation coefficient of 0.602 , we recognize that it is unrealistic to expect exponential growth for this length of time. For this reason, we wanted to examine the relationship between years and indemnities due to precipitation using a power regression model.

$\mathrm{W}(\mathrm{x})=(1726412.12) \mathrm{x}^{\wedge} 0.92800855$

The power model in Figure 6 seems to be the best fit for the scatterplot of indemnities paid due to precipitation against year, as the correlation coefficient is the strongest (compared to the linear and exponential models) at 0.628. Using the power model, we can make a prediction for the indemnity value in 2050 of:

$\mathrm{W}(59)=(1726412.12)(59) 0.92800855=\$ 75,946,940.62$

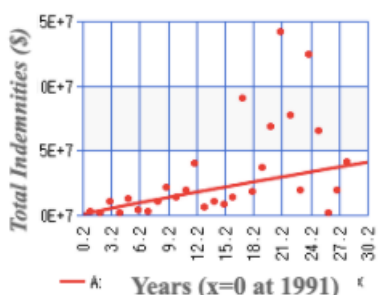

\begin{tabular}{|c|r|}
\hline function & \multicolumn{1}{|c|}{ value } \\
\hline mean of $\mathbf{x}$ & 11.29808998 \\
\hline mean of $\mathbf{y}$ & $16,381,065.58$ \\
\hline correlation coefficient $\mathbf{r}$ & $\mathbf{0 . 6 2 8 2 1 3 8 0 2}$ \\
\hline A & $1,726,412.12$ \\
\hline B & 0.92800855 \\
\hline
\end{tabular}

Figure 6: Indemnities paid in dollars (due to precipitation anomalies) per year from 1991-2018 for soybeans in.

\section{Step 9:}

Looking at our three models (Figures 4,5, and 6) for predicting indemnities paid due to precipitation (linear, exponential, and power), we decided that the linear and power models were more likely to give us an accurate prediction for 2050 .

Since our models are in terms of the value of the dollar in 1991, it was necessary to re-adjust our predictions for inflation, in order to estimate the actual value in 2050. Again, using a $3.22 \%$ inflation rate per year and the compound interest equation $\mathrm{A}=\mathrm{P}(1+\mathrm{r}) \mathrm{t}$, we adjusted our linear model and power model respectively. We used the number of years $(t)$ as 59 , since 1991 represents year 0.

From (6) we obtained the linear model prediction for indemnities paid of $\$ 141,786,302.90$, and adjusted this for inflation:

$\mathrm{I}(59)$ adj $=141,786,302.90(1+0.0322) 59=\$ 919,817,584.03$

From (8) we obtained the power model prediction for indemnities paid of $\$ 75,946,940.629$, and adjusted this for inflation:

$\mathrm{W}(59) \mathrm{adj}=75,946,940.629(1+0.0322) 59=\$ 492,694,498.80$

Using $\$ 492,694,498.80$ achieved from the power regression model $\mathrm{W}(\mathrm{x})$ as our lower bound, and $\$ 919,817,584.03$ achieved from the linear regression model $\mathrm{I}(\mathrm{x})$ as our upper bound, we can safely assume that total indemnity value due to precipitation anomalies in 2050 will be between $\$ 492,694,498.80$ and $\$ 919,817,584.03$

$\$ 492,694,498.80<$ Total indemnities due to precipitation in $2050<\$ 919,817,584.03$.

\section{Acknowledgements}

We sincerely thank the Actuarial Foundation for providing us with the opportunity to shed light on climate change and its effects on agriculture. We would like to express our sincere gratitude to our teacher Ms. Stephanie Machado who mentored us every step of the way. Thank you to Professor Susan Watson, Mr. Rod Ziolkowski, and Mr. Michael Johnston for their support as reviewers. We would like to also extend our thanks to Mr. Steven Ou, Ms. Sarika Jhagirdar, Mrs. Aditi Khisti, and Mr. Sivarama Vinjamury for their valuable insights and feedback.

Nafeesa Karim, Shravani Khisti, Anastacia Son, and Amrita Vinjamury equally contributed to the design and implementation of the research, to the analysis of the results, and to the writing of the manuscript.

\section{References}

1. Russaw, J. M. World Vegan Day 2019 Statistics: Plant-Based Diets On The Rise in the US, 2019. https://www.newsweek.com/ world-vegan-day-2019-statistics-1469069 (accessed January 25, 2020).

2. Goldsmith, P. Economics of Soybean Production, Marketing, and Utilization. ResearchGate[online].10.1016/B978-1-89399764-6.50008-1. December 2008. https://www.researchgate.net/ publication/267220413_Economics_of_Soybean_Production_ Marketing_and_Utilization (accessed March 17, 2020).

3. Karuga, J. WorldAtlas. https://www.worldatlas.com/articles/ world-leaders-in-soya-soybean-production-by-country.html (accessed February 12, 2020), 10 Countries with Largest Soybean Production.

4. Missouri Department of Agriculture Home Page. https:// agriculture.mo.gov/ (accessed December 20, 2019).

5. USDA RMA Home Page. https://www.rma.usda.gov/ (accessed January 25, 2020).

6. Janssen, E; Wuebbles, D. J.; Kunkel, K. E.; Olsen, S. C.; Goodman, A. Observational- and model-based trends and projections of extreme precipitation over the contiguous United States. Earth's Future [Online] 2014, 2, 99-113. AGU Publications. https:// agupubs.onlinelibrary.wiley.com/doi/10.1002/2013EF000185 (accessed February 12, 2020).

7. Lenssen, A. Soybean Response to Drought, 2012. Iowa State University, Department of Agronomy. https://crops.extension. iastate.edu/cropnews/2012/06/soybean-response-drought (accessed March 23, 2020). 
8. Pederson, P. Effect of Flooding on Emerged Soybeans, 2008. Iowa State University, Department of Agronomy. https://crops. extension.iastate.edu/cropnews/2008/06/effect-flooding-emergedsoybeans (accessed March 23, 2020).

9. Drennen, T. E.; Response of Soybean to Predicted Climate Change in the USA [Online]; Kaiser H. M.; Drennen T.; Drennen, T. E.; Taylor \& Francis: United States, 1993; pp. 117-130. https://www. google.com/books/edition/Agricultural_Dimensions_of_Global_ Climat/KiagIt4XGMMC?hl=en\&gbpv=0(accessed June 21, 2020).

10.Mall, R.K.; Lal, M.; Bhatia, V.S.; Rathore, L.S.; Singh, R. Mitigating climate change impact on soybean productivity in India: a simulation study. Agr. Forest Meteorol. [Online] 2004, 121,113-125.https://www.sciencedirect.com/science/article/pii/ S0168192303001576 (accessed March 13, 2020).

11.Curry, B. R.; Jones, J. W.; Boote, K. J.; Peart, M. R.; Hartwell, A. L. Jr.; Pickering, N. B. Climate Change and Agriculture: Analysis of Potential International Impacts [Online], Rosenzweig C.; Ritchie J. T.; Jones J. W.; Tsuji G. Y.; Hildebrand P.; American Society of Agronomy Inc., 2015; Volume 59. doi: https://doi. org/10.2134/asaspecpub59.c8(accessed February 23, 2020)

12.The Great Flood of 1993. NOAA National Weather Service https://www.weather.gov/dvn/071993_greatflood (accessed March 23, 2020).

13.Beef Bulking Up with Soy. United Soybean Board https://www. unitedsoybean.org/article/beef-bulking-up-with-soy(accessed February 27, 2020)

14.Matthew Wilde. Plant Soybeans Before Corn to Help Boost Yields. Progressive Farmer powered by DTN. https://www.dtnpf. com/agriculture/web/ag/crops/article/2019/11/11/plant-soybeanscorn-help-boost-2 (accessed February 11, 2020).

15.D. E. Carling; M. F. Brown. Relative Effect of VesicularArbuscular Mycorrhizal Fungi on the Growth and Yield of Soybeans. Soil Science Society of America Journal. https://doi. org/10.2136/sssaj1980.03615995004400030018x. Published Online: May 1, 1980.https://acsess.onlinelibrary.wiley.com/doi/ abs/10.2136/sssaj1980.03615995004400030018x (accessed March 13, 2020).

16.Practical Guide - Soil Management. Farming for a Better Climate https://www.farmingforabetterclimate.org/downloads/practicalguide-soil-management/(accessed February 20, 2020).

17.Hsaio, J. GMOs and Pesticides: Helpful or Harmful?. Science In the News Blog http://sitn.hms.harvard.edu/flash/2015/gmosand-pesticides/(accessed April 17, 2020), Harvard University The Graduate School of Arts and Sciences.

18.Missouri governor calls for $\$ 100 \mathrm{M}$ rainy day fund. KY3 https:// www.ky3.com/content/news/Missouri-governor-calls-for-100Mrainy-day-fund-567019321.html (accessed February 15, 2020).

19.Jones, C. Soybean Farmers' Fate Is Now In Chinese Hands. Forbes https://www.forbes.com/sites/chuckjones/2020/01/21/ soybean-farmers-fate-is-now-in-chinese-hands/\#2a489df72106 (accessed March 29, 2020).

20.Blumberg, A. Forget Stocks Or Bonds, Invest In A Lobbyist. National Public Radio https:/www.npr.org/sections/ money/2012/01/06/144737864/forget-stocks-or-bonds-invest-ina-lobbyist(accessed April 12, 2020).

21.Managing Soil and Soil Fertility After Flooding. SDSU Extension https://extension.sdstate.edu/managing-soil-and-soilfertility-after-flooding\#: :text=Flooding\%20Influences\%20 Plant\%2 DAvailable\%20Nutrients\&text=Deposition\%20of $\% 20$ sediments $\% 20$ from $\% 20$ floods, and $\% 20$ potentially $\% 20$ into \%20the\%20groundwater (accessed April 15, 2020).

22.Reisig, D., Dr., Carleo, J., Vann, R., Dr., \&amp; Hambrick, T. Pest
Avoidance Through Crop Management.https://soybeans.ces.ncsu. edu/pest-avoidance/ (accessed April 17, 2020), North Carolina State University

23.Biofuels. Energypedia https://energypedia.info/wiki/Biofuels (accessed March 30, 2020).

24.Fossil Fuels Have Made Up At Least $80 \%$ of US Fuel Mix Since 1900. US Energy Information Administration https://www.eia. gov/todayinenergy/detail.php?id=21912 (accessed March 29 2020).

25.How much oil does the U.S. export and import?. American Geosciences Institute. https://www.americangeosciences.org/ critical-issues/faq/how-much-oil-does-us-export-and-import (accessed March 30, 2020).

26.Khanna, M; Crago, C, L; Black, M. Can biofuels be a solution to climate change? The implications of land use change-related emissions for policy. Interface Focus [Online] 2011, 1, 233-247. doi:10.1098/rsfs.2010.0016.https://royalsocietypublishing.org/ doi/10.1098/rsfs.2010.0016 (accessed March 16, 2020).

27.Diesel vs. Biodiesel vs. Vegetable Oil. Consumer Reports https:// www.consumerreports.org/cro/2012/05/diesel-vs-biodiesel-vsvegetable-oil/index.htm (accessed April 2, 2020), 2014.

28. Pimentel, D; Marklein, A; Toth, A, M; etc. Food Versus Biofuels: Environmental and Economic Costs. Springer Science and Business Models2009, DOI 10.1007/s10745-009-9215-8. Research Gate. https:/www.researchgate.net/ publication/225484051_Food_Versus_Biofuels_Environmental_ and_Economic_Costs(accessed November 22, 2020).

29.Larson, L, W; Destructive Water: Water-Caused Natural Disasters - Their Abatement and Control. Presented at IAHS Conference [Online], Anaheim, California, June 24-28, 1996. The Great USA Flood of 1993. https:/www.nwrfc.noaa.govfloods/ papers/oh_2/great.htm (accessed February 20, 2020).

30.Climate Science Special Report: Fourth National Climate Assessment. US Global Change Research Program [Online].2017,Volume I, chapter 8. https://science2017. globalchange.gov/(accessed February 12, 2020).

31.McMahon, T. Long Term U.S. Inflation. Inflation Data https:// inflationdata.com/Inflation/Inflation_Rate/Long_Term_ Inflation.asp (accessed March 20, 2020), April 1, 2014.

\section{Authors}

Shravani Khisti is a senior and has a passion for scientific research. She is planning on majoring in neurobiology and bioinformatics but actively enjoys widening her scope of knowledge towards other fields. She hopes to one day, conduct research in the field of medicine.

Anastacia Son is a senior and is passionate about social science. She is planning to pursue law, political science, data science, or psychology. She hopes to one day be involved in policy making in public health or other sectors.

Nafeesa Karim is a senior who is interested in doing research on a variety of topics. She is planning to go into mechanical or aerospace engineering, and is interested in space, climate/ energy issues, and computer science.

Amrita Vinjamury is a senior who is very interested in statistical modeling. She plans on majoring in applied mathematics with an emphasis in decision making. She hopes to further her career in the field of statistics in order to maximize her impact in the world. 
or aerospace engineering, and is interested in space, climate/ energy issues, and computer science.

Amrita Vinjamury is a senior who is very interested in statistical modeling. She plans on majoring in applied mathematics with an emphasis in decision making. She hopes to further her career in the field of statistics in order to maximize her impact in the world. 